\title{
Mass spectral determination of phenylacetonitrile (PAN) levels in body tissues of adult desert locust, Schistocerca gregaria
}

Peris W. Amwayi ${ }^{a, b}$, Daniel K. Masiga ${ }^{a}$, Prem Govender ${ }^{b, c}$, Peter E. A. Teal ${ }^{d}$, Baldwyn Torto ${ }^{a^{*}}$

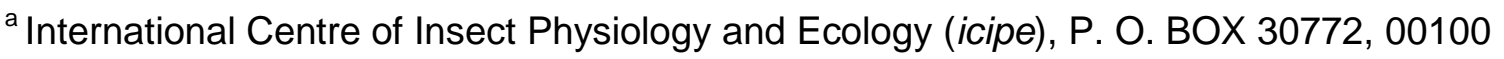
Nairobi, Kenya

${ }^{\mathrm{b}}$ Department of Zoology and Entomology, University of Pretoria, Pretoria, South Africa

${ }^{\mathrm{c}}$ Department of Biology, University of Limpopo, Medunsa Campus, South Africa

${ }^{\mathrm{d} U S D A}$ ARS-Centre for Medical, Agricultural and Veterinary Entomology, Gainesville, Florida, USA

\section{ABSTRACT}

Wings and legs of the gregarious desert locust, Schistocerca gregaria have been shown to be release sites of phenylacetonitrile (PAN), the major adult male-produced pheromone. However, there is limited information on the distribution of PAN within the locust. Here we show, using gas chromatography - mass spectrometry (GC-MS), that PAN occurs in nearly all body parts of both adult males and females of the locust in varying amounts. PAN was 20 -fold more concentrated in males than in females. In females, PAN was concentrated more in the tarsal segments. The greatest amounts of PAN were in 2- and 3-week old female and male body parts, respectively. No trace of PAN was found in similar ages and sexes of the solitarious phase desert locust. Our results show that PAN is distributed in the body matrix of both sexes of gregarious phase locusts and suggest that no specific tissue is responsible for biosynthesis of the pheromone

KEY WORDS

Schistocerca gregaria, phenylacetonitrile, pheromone, locust, mass

spectrometry 


\section{INTRODUCTION}

Phenylacetonitrile (PAN) was identified as the principal component of the adult aggregation pheromone of the desert locust Schistocerca gregaria (Orthoptera:Acrididae) in the 1990s (Torto et 1994). Subsequent studies have demonstrated the multiple behavioural and reproductive functions for the pheromone in this notorious agricultural pest (Ferenz, 1990; Loher, 1990; Byer, 1991; Seidelmann et al., 2000; Ferenz and Seidelmann, 2003; Rono et al., 2008; Bashir and Hassanali, 2010). The major pheromone component of the gregarious adult males has been shown to be involved in cohesive behaviour of the desert locusts at lower relative concentrations (Torto et al., 1994) and as male-male homosexual repellent at higher relative concentrations (Seidelmann and Ferenz, 2002; Siedelmann et al 2005; Rono et al., 2008).

Based on histological studies, abdominal epidermal cells have been suggested as the possible site of production of the pheromone (Loher, 1961; Loher, 1990). These epidermal cells are large and vacuolated in the gregarious phase of male locusts when they became sexually mature, but are undeveloped in immature males and females and solitarious locusts. Despite being in the abdomen, the occurence of this enlarged vacuolated epidermal cells has also been reported in other body parts of the locust including tarsal segments of the legs (Kendall, 1972). Subsequent studies, suggested that phenylacetonitrile and benzaldehyde, the biosynthetic products of phenylalanine are produced in the epidermal pheromone producing cells of the wings and legs (Seidelmann, 2003), where distinct body parts of the gregarious male desert locust were analyzed using solid-phase-microextraction (SPME). Therefore, we undertook a study to determine if anatomical tissues other than the wings and legs in both sexes, phases and different ages contain PAN. This could lead to the identification of possible enzymes and genes involved in PAN biosynthesis for future development of locust control strategy. The following, 
report results of studies in which we analyzed extracts of different tissues by GC-MS to determine (i) the presence of PAN in various body parts and (ii) age related variations in the amounts of the pheromone in both males and females of the two phases of desert locust.

\section{MATERIALS AND METHODS}

\section{Insects}

The gregarious locusts were reared at the Insect and Animal Breeding Unit (IABU) of icipe. The colony originated from the Centre's Port Sudan field station in Sudan. About $200-250$ of these insects were reared under crowded conditions in aluminium cages $(50 \times 50 \times 50 \mathrm{~cm})$ in a special room $(4.5 \times 4.5 \mathrm{~m})$ each well aerated with a duct system to maintain a negative pressure. However, the solitarious reared adult insects were kept individually in standard aluminium cages $(10 \times 10 \times 24 \mathrm{~cm})$ in visual olfaction and tactile isolation from other insects. The solitarious colony originated from Dr. Steve Roger, Department of Zoology, University of Cambridge. In both phases of the desert locusts, the rooms were maintained at a temperature of $30 \pm 4{ }^{\circ} \mathrm{C}, 40$ - $50 \%$ relative humidity $(\mathrm{RH})$ and a photoperiod of 12:12 L/D (Ochieng-Odero, 1994). The insects were fed on fresh wheat seedlings and bran daily.

\section{Extracts}

Both males and females of crowd-reared and solitarious-reared adult stages of the desert locust were used in this study. Relative concentration of PAN from extracts of different body parts according to age (five ages after fledgling namely $0,1,2,3$ and 4 week old) males and females were analyzed by GC-MS. The following body tissues were used: fat body, and accessory gland (males and females), testis, ovaries and phallic complex (from males), ovaries and spermatheca (from females). The insects were chilled and dissected under physiological saline. The body 
parts were transferred into vials containing $1 \mathrm{ml}$ hexane solution (Sigma Aldrich). External body parts were obtained from whole wing, femur, tibia and tarsus from both males and females, then cut into smaller pieces per individual insect and transferred to $1 \mathrm{ml}$ of hexane. The weights of all the body parts were recorded. All the body parts were soaked in $1 \mathrm{ml}$ hexane for $10 \mathrm{~min}$ followed by homogenization using a vortex for $5-10 \mathrm{~min}$. The extract was then obtained by decanting the hexane. An aliquot $(1 \mu \mathrm{l})$ of methyl salicylate $(\sim 150 \mathrm{ng})$ was added to $40 \mu \mathrm{l}$ of each hexane extracted sample as the internal standard to determine the quantity of PAN per mg of body part. Three replicates of each body parts were used in this study. Each replicate represent different insects. In cases where the body parts were too small, the body parts were pooled, the weights were taken and the total quantity of PAN per weight per insect determined.

\section{Chemical analysis}

Gas chromatography-mass spectrometric (GC-MS) analysis and identification of compounds within each sample was conducted using an Agilent technologies $7890 A \circledast$ series GC coupled to a 5975C Triple Axis MSD $\AA$. The mass spectrometer has an overall mass scan range of $\mathrm{m} / \mathrm{z} 1$ 1050 and was calibrated using heptacosa (Perfluorotributylamine) $\left[\mathrm{CF}_{3}\left(\mathrm{CF}_{2}\right)_{3}\right]_{3} \mathrm{~N}$ (Apollo Scientific Ltd. UK) and set to acquire data over the range of $\mathrm{m} / \mathrm{z}$ 38-550 respectively. The electron ionization (EI) mode was used with electron energy set at $70 \mathrm{eV}$ and emission current of $34.6 \mu \mathrm{A}$. The temperature of the ion source was held at $230{ }^{\circ} \mathrm{C}$, the Quadrupole at $150{ }^{\circ} \mathrm{C}$ with the multiplier voltage at $1106 \mathrm{~V}$. The pressure of the ion source was held steady at $8.4 \times 10^{-}$ ${ }^{6} \mathrm{mBar}$. A data acquisition scan cycle of 3 scans per $2 \mathrm{sec}$ was used.

Samples were injected in the splitless mode and the injector was purged at $0.8 \mathrm{~min}$ at an injector temperature of $270{ }^{\circ} \mathrm{C}$. Helium was used as a carrier gas at a linear flow velocity of $39.621 \mathrm{~cm} / \mathrm{sec}$. GC oven was held at an initial temperature of $35 \stackrel{\circ}{\circ} \mathrm{C}$ for $5 \mathrm{~min}$, and then 
increased at a rate of $10^{\circ} \mathrm{C} / \mathrm{min}$ up to $280^{\circ} \mathrm{C}$ for $10.5 \mathrm{~min}$ then $50^{\circ} \mathrm{C}$ to $285^{\circ} \mathrm{C}$ for $9.9 \mathrm{~min}$, the total run time was 50 min. A HP5-MS low bleed GC-MS capillary column, with dimensions $30 \mathrm{~m}$ x $0.25 \mathrm{~mm}$ (i.d) $\times 0.25 \mu \mathrm{m}$ (film thickness) supplied by $\mathrm{J} \& \mathrm{~W}$ Scientific was used for separation of compounds in the extracts.

The GC-MS was linked to a computer with MS library and PAN was identified by comparing its retention time and spectra of authentic standards.

\section{Quantification}

GC-MS in selected ion monitoring mode (SIM) was used to detect PAN in the extracts. Two ions monitored in PAN were $\mathrm{m} / \mathrm{z} 90$ and 117 while the selected ions for internal standard, methyl salicylate were $\mathrm{m} / \mathrm{z} 92,120$ and 152 . Serially diluted solutions of synthetic PAN (Sigma Aldrich) (1 $\mathrm{ng} / \mu \mathrm{l}-10 \mathrm{ng} / \mu \mathrm{l}$ ) were analyzed by GC-MS in SIM mode to obtain linear calibration curves (Mass area vs. concentration) which served as the basis for the external quantification.

\section{Data Analysis}

The data on the amount of PAN in the internal and external tissues of each sex were analyzed separately. Analysis of amounts of PAN in each sex was performed week by week using multiway ANOVA in the R 2.13.2 statistical package. Means were separated by Student-NewmanKeul (SNK) test at $5 \%$ level of significance.

\section{RESULTS}

Calibration approaches for PAN quantification 
The quantification of PAN from the tissues of the desert locust was based on two calibration approaches, internal and external quantification. The standard calibration curves using synthetic PAN showed good linearity within the range of $1 \mathrm{ng} / \mu \mathrm{l}-10 \mathrm{ng} / \mu \mathrm{l}$ as shown in Figure 1 .

\section{PAN amounts with age}

The results of the GC-MS analyses of the amounts of PAN in both males and females with age are shown in Figures 2 and 3, respectively. There were quantitative differences in amounts of pheromone associated with increasing age. No significant difference in the amount of PAN in different body parts was evident during the first week after fledgling. However, the amount of PAN increased significantly the following week (two weeks after fledgling) with the onset of sexual maturation. Extracts from both external and internal body parts contained more PAN in the second week showing age related differences in both sexes.

\section{PAN amounts in both sexes}

The body parts with the highest levels of PAN were detected in 3-week-old males and 2-weekold females respectively. The body parts of females contained PAN but in lower concentrations compared to their male counterparts. There was a significant difference in amounts of PAN in extracts from external and internal tissues with external body parts of both sexes containing the highest amounts of PAN. The mean PAN amount (mean \pm SE) in extracts from 3-week-old males followed the order in decreasing amounts; wings $(77.82 \pm 4.51 \mathrm{pg} / \mathrm{mg})$, tarsi $(28.35 \pm 0.84$ $\mathrm{pg} / \mathrm{mg})$, tibia $(18.27 \pm 1.58 \mathrm{pg} / \mathrm{mg})$ and femurs $(6.21 \pm 0.54 \mathrm{pg} / \mathrm{mg})(\mathrm{p}<0.01, \mathrm{~F}=44.48$, DF $=$ 3). In females, tarsi had the highest amount of PAN at 2 weeks ( $3.54 \pm 0.36 \mathrm{pg} / \mathrm{mg}$ ), followed by tibia $(1.43 \pm 0.09 \mathrm{pg} / \mathrm{mg})$, wings $(0.80 \pm 0.01 \mathrm{pg} / \mathrm{mg})$ and femurs $(0.28 \pm 0.03 \mathrm{pg} / \mathrm{mg})(p<0.001$, $F=57.25, D F=3$ ). PAN in the internal body parts of both sexes was found to be in relatively small amounts (Figures $1 \mathrm{~b}$ and $2 \mathrm{~b}$ ). Fat bodies were amongst the highest PAN containing 
internal tissue in both sexes with $(4.02 \pm 0.44 \mathrm{pg} / \mathrm{mg})$ in males and $(0.91 \pm 0.22 \mathrm{pg} / \mathrm{mg})$ in females. Also, separated females at 2 weeks and 3 weeks produced PAN amounts of $4.30 \pm$ $0.46 \mathrm{pg} / \mathrm{mg}$ and $2.55 \pm 0.52 \mathrm{pg} / \mathrm{mg}$ respectively from the tarsi.

\section{PAN amounts with phase}

No PAN was detected in any body part of solitarious reared locust of 1-, 2-, 3- and 4-week of age in both males and females after fledgling in comparison with their gregarious reared locust counterparts.

\section{DISCUSSION}

This study was used to demonstrate the ability of GC-MS to detect and quantify even small amounts of PAN in various body parts of the desert locust and to document that there were both age- and sex-related differences in amounts of PAN present in various tissues of the locust. The increase in the amount of PAN from tissues with age correlated well with the earlier findings that showed increased headspace volatile amounts with age (Mahamat et al., 1993; Ferenz et al., 1994; Torto et al., 1994; Seidelmann et al., 2000). However, PAN was present in the body parts of both males and females although tissues from males contained 20 -fold more PAN compared with the females. To our knowledge, this is the first study that detects amounts of PAN in the body parts of female. This indicates that the pheromone is present in both sexes but the release of this pheromone is restricted to sexually mature adult gregarious males. The presence of PAN in gregarious but not in solitary locusts has been attributed to the aggregation behavior of the desert locust.

Recent studies have shown that the production of PAN coincided with the onset of sexual maturity (Mahamat et al., 1993; 2000; Deng et al., 1996). This is supported in our study where 
most PAN was present in 2-week-old females and conversely in 3-week- old males. However, the amount of PAN in 2-week-old males was significantly higher than in females of the same age. A previous report indicated that pentanoic acid, a compound associated with 'female locust pheromone' produced by the Comstock-Kellog glands (CKGs) was found more in 2-week old females (Njagi et al., 2002). The results of this study also show a similar trend in the presence of PAN in females, a likely indicator that females mature faster than males based on both PAN and pentanoic acid production. Also, the females produced PAN regardless of the presence or absence of males in a cage. It is therefore unlikely that the females get it through contact from their male counterparts. Headspace volatile collection of PAN also shows traces amounts of PAN from females, an indication that they might be producing it too. However, the role of PAN in the adult female locust is still unknown.

In our study, the wings had the highest amounts of PAN in males which concurred with previous data (Seidelmann et al., 2003). However a remarkable feature in our study was the ubiquitous presence of PAN in extracts of all tissues analyzed from both sexes with a greater distribution of the pheromone on the external rather than internal tissues. Seidelmann et al. (2003) reported the occurrence of veratrole, another typical component of the adult male volatile in all body parts. In flour beetles, the aggregation pheromone was shown to occur in the exocrine glands on the ventral side of the first pair of femur (Olsson et al., 2006). The results of our study suggest that the potential origin of PAN production is an external (body part based on the high amounts found on the wings and legs). However, the concurrent detection of the PAN in internal tissues indicates that the pheromone may be produced in multiple locations in the body. This could be attributed to the presence of glandular epidermal cells in nearly all body parts of the desert locusts (Kendall, 1972). The broad distribution of PAN in the epidermis of the desert locust maybe an important mechanism for faster release and dispersion of the pheromone. 
Earlier reports showed concentration-dependent responses to PAN by S. gregaria males (Rono et al., 2008). There was evidence of arrestment (Torto et al., 1994) of individuals closer to a PAN source at low relative doses but repellent characteristics (Seidelmann and Ferenz, 2002) at higher doses. It is possible that, accumulating high concentrations of PAN could be toxic to the locusts hence it appears the locusts have developed a mechanism to disperse it rapidly from the body tissues. This would easily be accommodated by wing fanning and would explain why wings of males contain the largest amounts of PAN.

In conclusion, our results have demonstrated that both males and females of the desert locust produce PAN and indicate a strong correlation between its production and sexual maturity. Our research has documented that virtually all tissues contain detectable amounts of PAN, findings that provide leads on tissues that should be further examined as sites of biosynthesis, transportation and distribution of PAN in the body of the locust.

\section{Acknowledgements}

We thank USDA, DAAD and ARPPIS for supporting the research project at icipe. We acknowledge the assistance of various staff at the icipe BCED department.

\section{REFERENCES}

Bashir MO, Hassanali H (2010) Novel cross-stage solitarising effect of gregarious-phase adult desert locust Schistocerca gregaria (Forskål) pheromone on hoppers. J Insect Physiol 56: $640-645$.

Byer JA (1991) Pheromones and chemical ecology of locusts. Biol Rev 66: 347-378.

Deng AL, Torto B, Hassanali A, Ali E (1996) Effects of shifting to crowded or solitary conditions on pheromone release and morphometrics of the desert locust, Schistocerca gregaria (Forskål)(Orthoptera: Acrididae). J Insect Physiol 42: 771-776. 
Ferenz H (1990) Locust pheromones- Basic and applied aspects. Boletin de Sanidad Vegetal, Fuere de Serie No 20 (also as Proceeding of the 5th International Meeting of the Orthopterists' Society 1989): 29-37.

Ferenz HJ, Luber K, Wieting J (1994) Pheromones as a means of controlling migratory locusts. In: Krall, S, Wilps, H (Eds), New trends in locust control Schriftenreihe der GTZ, No 245 GTZ, Eschborn: 81-89.

Ferenz HJ, Seidelmann K (2003) Pheromones in relation to aggregation and reproduction in desert locusts. Physiol Entomol 28: 11-18.

Kendall MD (1972) Glandular epidermis on the tarsi of the desert locust, Schistocerca gregaria. Acrida 1: 121- 147.

Loher W (1961) The chemical acceleration of the maturation process and its hormonal control in the male of the desert locust. Proceedings of the Royal Society B 153 (1960): 380-397. Loher W (1990) Pheromones and phase transformation in locusts. In: Chapman, RF, Joern, A (Eds), Biology of Grasshoppers John Wiley, New York: 337-355.

Mahamat H, Hassanali A, Odongo H, Torto B, El Bashir S (1993) Studies on the maturationaccelerating pheromone of the desert locust Schistocerca gregaria (Orthoptera: Acrididae). Chemoecol 4: 159-164.

Mahamat $\mathrm{H}$, Hassanali A, Odongo $\mathrm{H}(2000)$ The role of different components of the pheromone emission of mature males of the desert locust, Schistocerca gregaria (Forskål) (Orthoptera: Acrididae) in accelerating maturation of immature adults. Insect Sci Appl 20: $1-5$.

Njagi PGN, Torto B (2002) Evidence for a compound in Comstock-Kellog glands modulating premating behavior in male desert locust, Schistocerca gregaria. J Chem Ecol 28: 10651074 
Ochieng-Odero JPR, Ndugo SM, El Bashir S, Capstick PB (1994) A method for rearing crowded (gregarious) and isolated (solitary) locusts (Orthoptera: Acrididae) in the laboratory In: Njagi, P.G.N., Chaudhury, M.F.B. (Eds.). Proceedings of the Workshop on Effective Networking of Research and Development on Environmentally Sustainable Locust Control Methods among Locust-Affected Countries ICIPE Science Press, Nairobi, Kenya: 33-44.

Olsson CPO, Ryne C, Wallén R, Anderbrant O, Lofstedt C (2006) Male produced sex pheromone in Tribolium confusum: Behaviour and investigation of pheromone production locations. J Stored Products Res 42: 173-182.

Rono E, Njagi PGN, Bashir MO, Hassanali A (2008) Concentration-dependent parsimonious releaser roles of gregarious male pheromone of the desert locust, Schistocerca gregaria. J Insect Physiol 54: 162-168.

Seidelmann K, Luber K, Ferenz HJ (2000) Analysis of release and role of benzyl cyanide in male desert locusts, Schistocerca gregaria. J Chem Ecol 26: 1897-1910.

Seidelmann K, Ferenz HJ (2002) Courtship inhibition pheromone in the desert locust, Schistocerca gregaria. J Insect Physiol 48: 991-969.

Seidelmann K, Weinert H, Ferenz HJ (2003) Wings and legs are production sites for the desert locust courtship-inhibition pheromone, phenylacetonitrile. J Insect Physiol 49: 11251133.

Torto B, Obeng-Ofori D, Njagi PGN, Hassanali A, Amiani H (1994) Aggregation pheromone system of adult gregarious desert locust Schistocerca gregaria (Forskal). J Chem Ecol 20: $1749-1762$.

Figure 1. Calibration curve of synthetic PAN used for external quantification of PAN in the extracts. The mass area of the peak obtained from different concentrations of synthetic PAN was used to draw this curve. 
Figure 2. Mean phenylacetonitrile ( $P A N \pm S E$ ) amounts determined from differing ages of the male S. gregaria. (A) external and (B) internal body parts.

Figure 3. Mean phenylacetonitrile ( $P A N \pm S E$ ) amounts determined from differing ages of the female S. gregaria. (A) external and (B) internal body parts. 


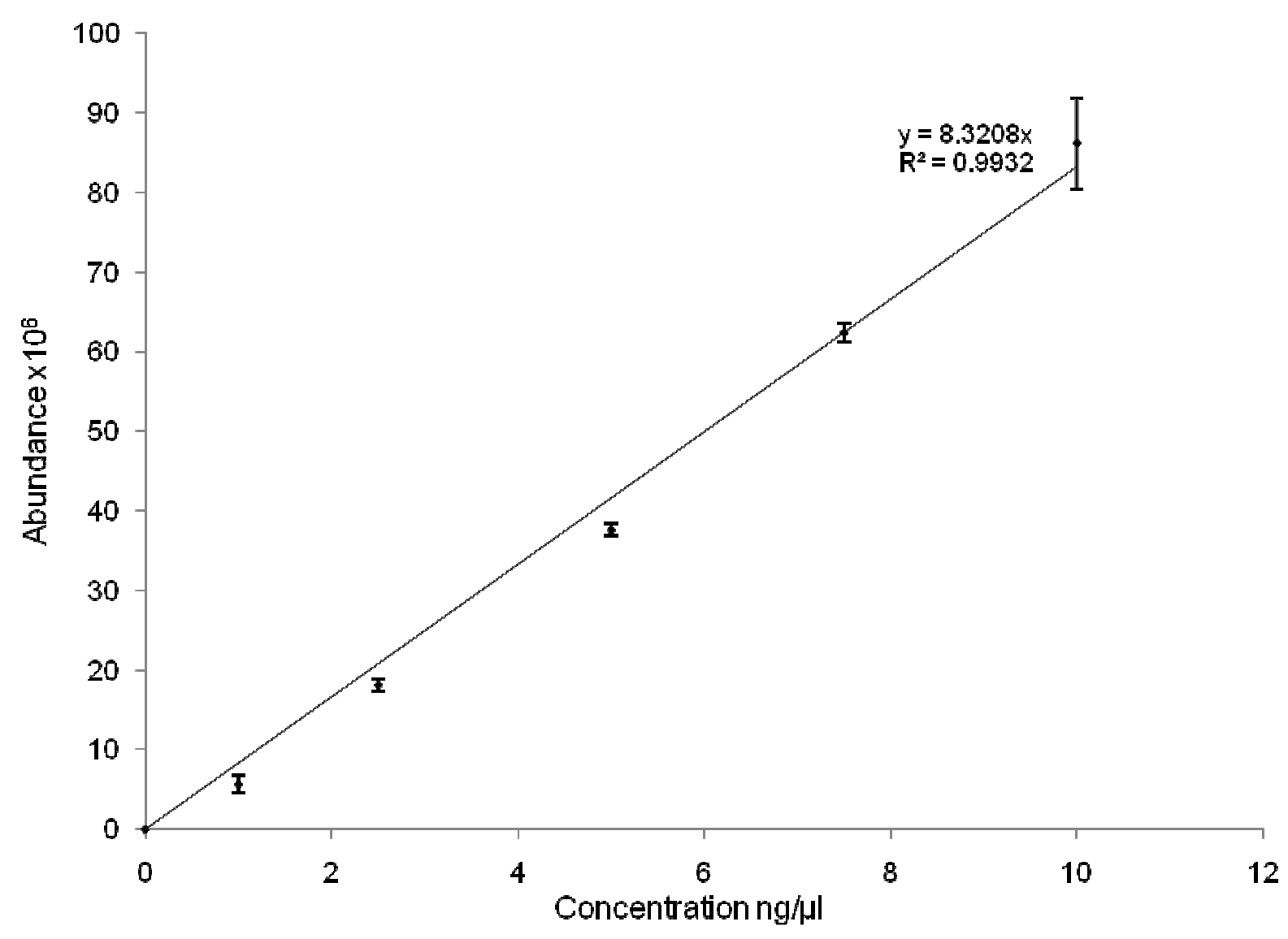

Figure 1 
A

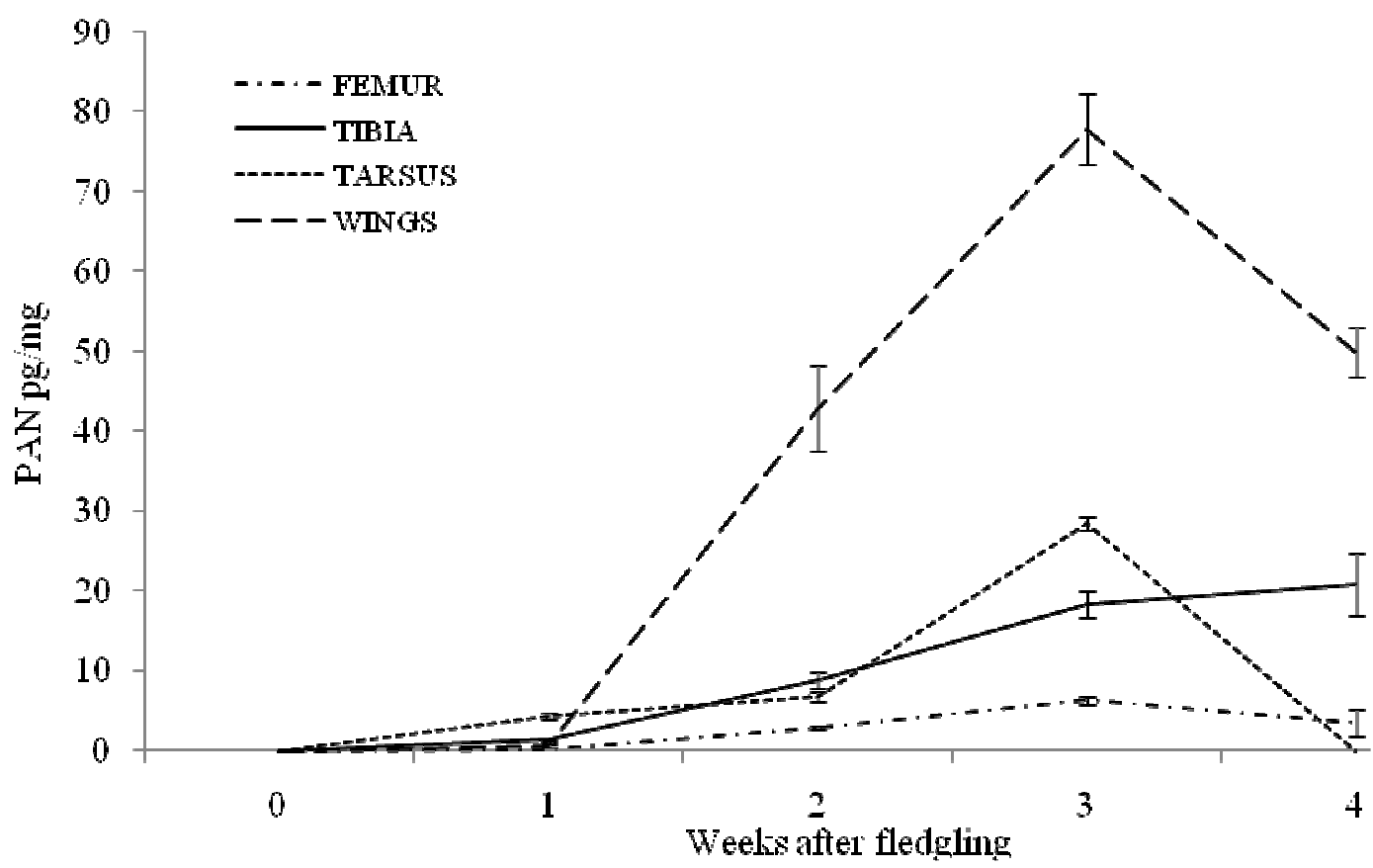

B

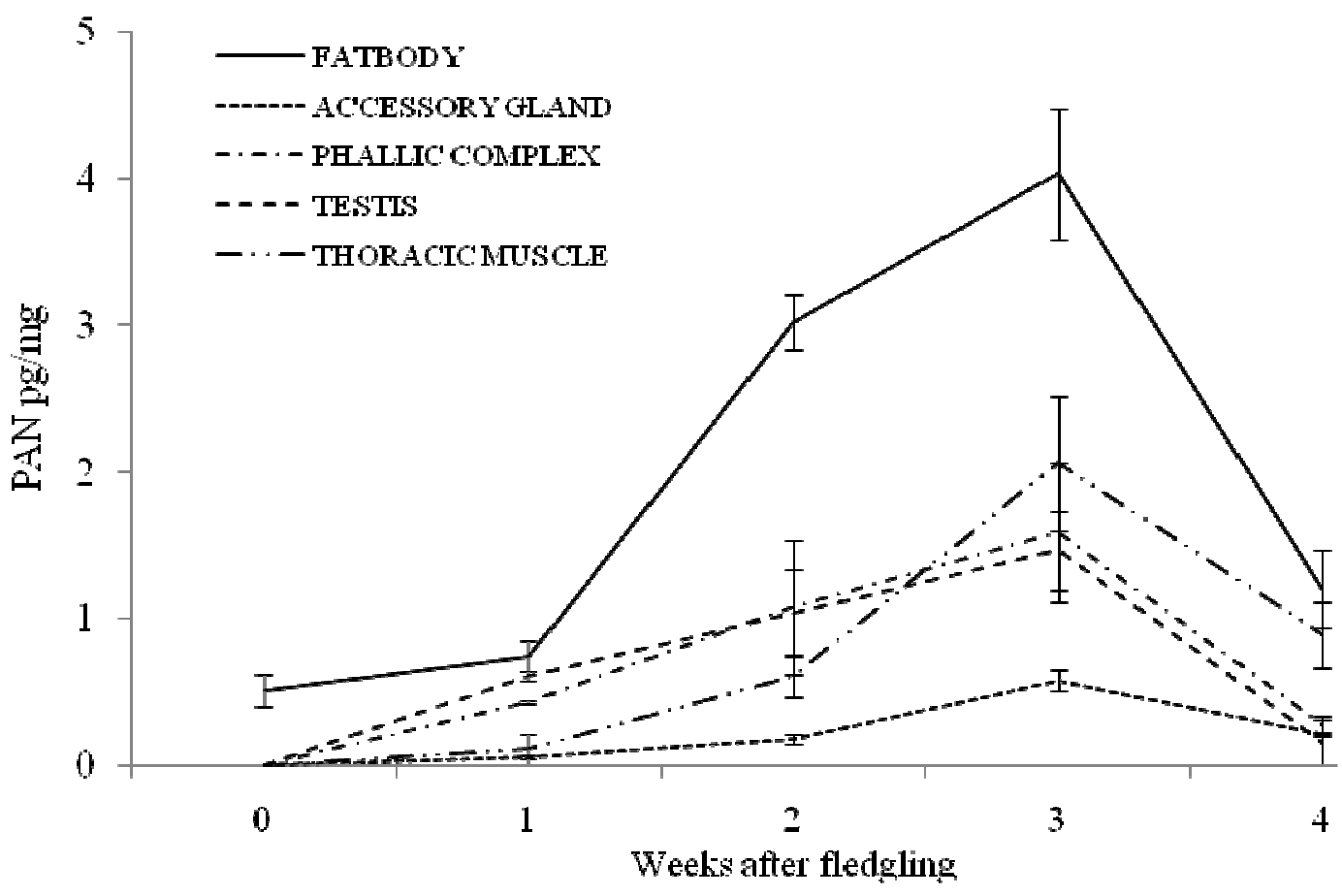

Figure 2 


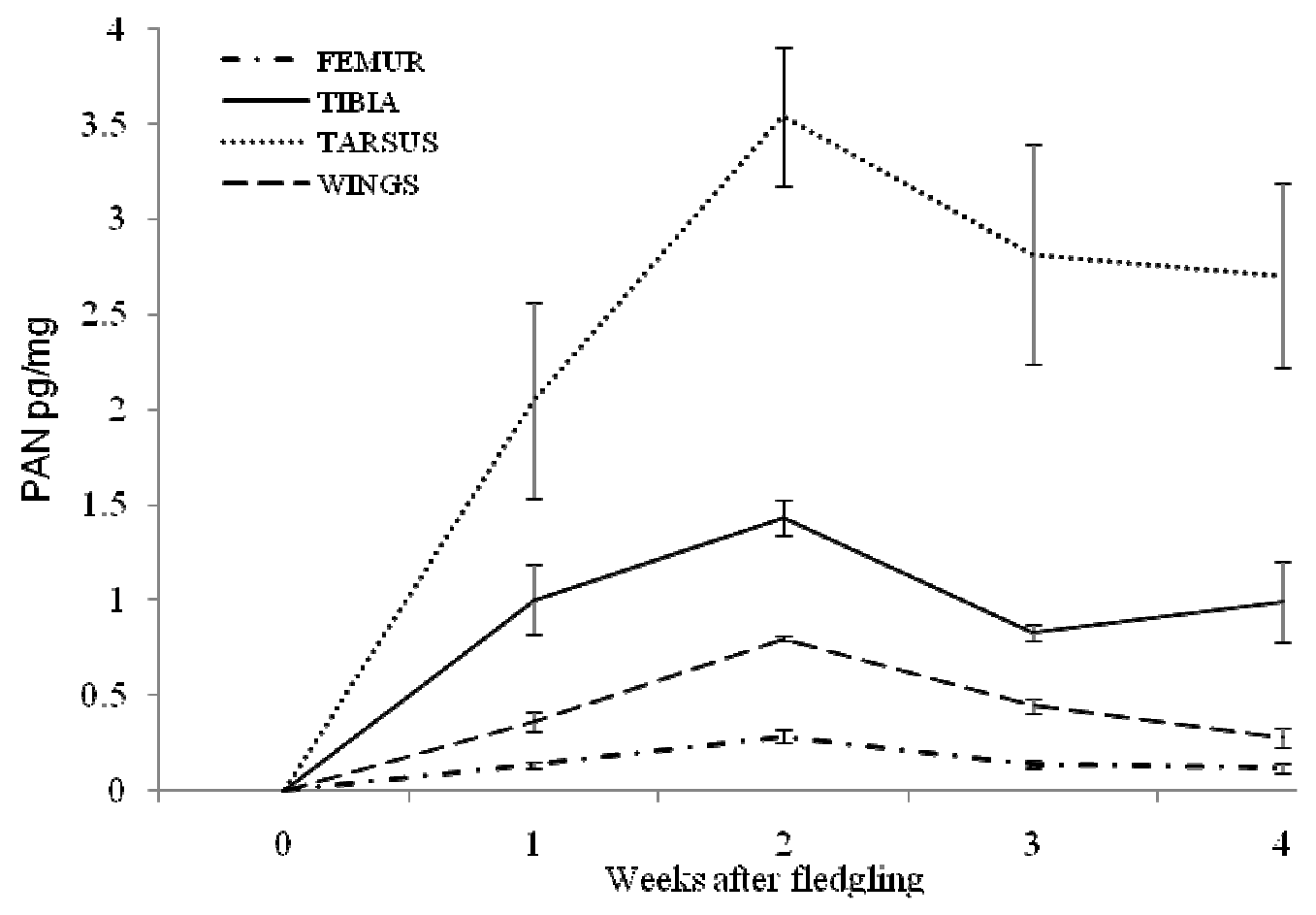

B

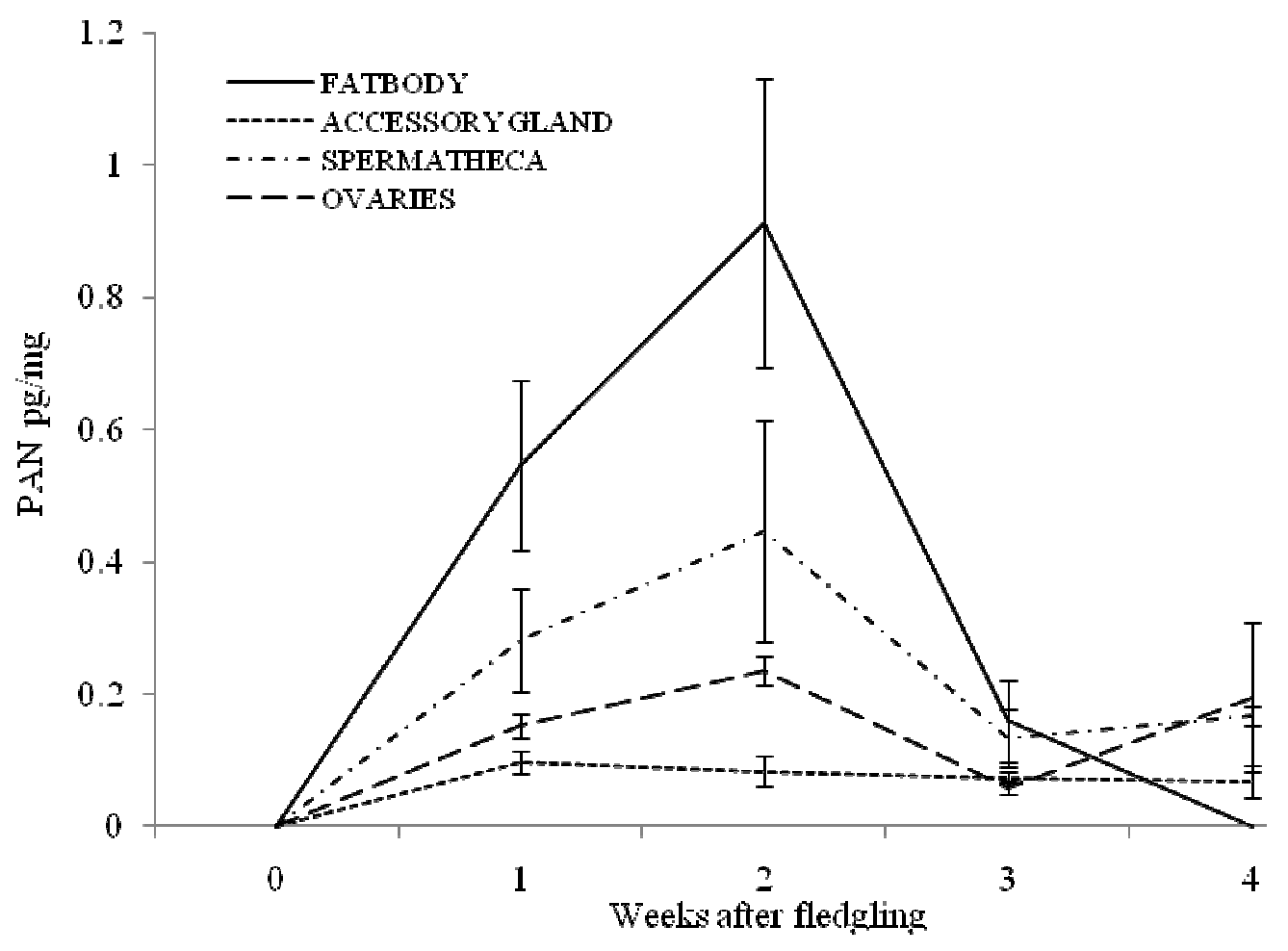

Figure 3. 